\title{
Opinion Versus Reality: How Should Wrongfully Convicted Individuals Be Compensated Versus How They Are Actually Compensated
}

\author{
Jeremy Shifton \\ Department of Criminal Justice at Oswego, SUNY \\ U.S.A.
}

Securing compensation following exoneration is an important step for wrongfully convicted individuals in getting some semblance of a normal life post-release. This study seeks to determine what the public believes to be fair compensation for individuals who were wrongfully incarcerated for ten years prior to exoneration, as compared to how much compensation a state would offer the same exoneree. Prior research has tracked what compensation is offered to exonerees through state statutes and detailed difficulties in securing compensation at trial, yet little is known about how statutory compensation compares to what the public believes exonerees should receive. Through two experimental surveys, the current study surveys over 200 students and online respondents to determine how much compensation is fair to individuals and compares these amounts to what states give to qualifying exonerees. Results indicate that individuals give more compensation on average to a fictional exoneree than do state governments; though the dollar amounts were not statistically significantly different, respondents gave millions more to exonerees than did state statutes. The significance of these findings and avenues for future research are examined.

I. Introduction and Literature Review
A. Compensation Research
B. Surveys of Wrongful Convictions
C. Impact of Compensation on the Criminal Justice System
D. Current Study

II. Method
A. Students
B. General Population
C. State Statutes

III. Results
A. Students
B. General Population
C. State Statutes
D. Hypotheses and Other Considerations

IV. Discussion

A. Limitations and Future Research

B. Concluding Remarks 


\section{Introduction and Literature Review}

Walter Ogrod was convicted in 1996 of murder and child sex abuse in Philadelphia, Pennsylvania and was sentenced to death. He was exonerated in 2020 with the help of DNA evidence after serving 24 years in prison (Possley, 2021a). Lacino Hamilton was convicted in 1995 of murder and illegal use of a weapon in Detroit, Michigan and was sentenced to 52-82 years, potentially a death sentence for an individual who was 20 years old at the time of conviction. He was exonerated in 2020 with the help of DNA evidence after serving 25 years in prison (Possley, 2021b). While these two men suffered similar fates by being wrongfully convicted and incarcerated for more than two decades, their outcomes after exoneration will in part be determined by whether they receive compensation.

In June 2021, Walter Ogrod filed a federal lawsuit against the city of Philadelphia and several Philadelphia police officers in the hopes of securing compensation because Pennsylvania does not have any statutory compensation for exonerees. Pennsylvania has historically yielded compensation to exonerees claiming malicious prosecution in only 37\% of their cases (Melamed, 2021). Lacino Hamilton filed a claim for compensation from the state of Michigan in October 2020; according to Michigan statute, Hamilton is entitled to $\$ 50,000$ per year of incarceration and should be awarded \$1.25 million for the time he served. While both Hamilton and Ogrod suffered for years for crimes they did not commit, only one of them can reasonably expect to receive recompense for two dozen years of suffering.

As of July 2021, the U.S. Federal Government, the District of Columbia, and 36 states have compensation statutes that grant either money, social services, or both to wrongfully convicted and exonerated individuals. That 14 states have no compensation laws at all is shameful, adding further injury to that already borne by exonerees. There is widespread support for government compensation of all wrongfully convicted individuals, yet little in terms of research into exactly how much compensation should be given (Clow et al., 2012; Clow \& Ricciardelli, 2014; Karaffa et al., 2015). The current research surveyed students and laypersons in order to help explain how the current state of compensation statutes compares to what individuals feel is "fair compensation" for exonerees.

Wrongfully convicted individuals who are eventually exonerated were subjected to unfathomable difficulties as a result of their imprisonment. Those lucky few who are eventually recognized as innocent were incarcerated for an average of nine years (National Registry of Exonerations). During that time, as well as after release, exonerees struggle with mental, physical, and financial health and wellbeing, have difficulties finding work and housing and building and maintaining relationships, and endure still other difficulties beyond their control. One of the ways this suffering can be alleviated is by guaranteeing compensation to all exonerated individuals. The current patchwork system of state and Federal statutory compensation is not guaranteed, as there are procedural hurdles to navigate. Receiving statutory compensation is still far more likely in 36 states and the District of Columbia than it is in the 14 states where an exoneree's only hope is to receive a payout from a lawsuit. This study describes how current state statutes compare to what individuals believe is fair compensation for exonerees to argue that guaranteed compensation is necessary for individuals as well as the criminal justice system as a whole. 


\section{A. Compensation Research}

For more than 20 years, research has highlighted just how poorly exonerees fare when seeking compensation, even in states that offered it, and has advocated for increases in compensation amounts and decreases in statutory hurdles that made it difficult for exonerees to actually receive compensation (Bernhard, 1999; 2004; 2009). While the steady increase in the number of states offering statutory compensation is better than the alternative, progress has been slow. Bernhard $(1999 ; 2004)$ noted that since their initial research which highlighted the dearth of easily accessible compensation, only two states added compensation statutes in the intervening years. Nevertheless, these and other studies have no doubt contributed to an environment where the plight of exonerees has increasingly been recognized.

In the $21^{\text {st }}$ century, many compensation studies have prescribed changes to the current system, arguing for additional compensation, social support services, and individualized compensation plans for exonerees while contrasting state statutes with federal civil rights and state tort lawsuits (Chunias \& Aufgang, 2008; Lonergan, 2008; Mostaghel, 2011; Simms, 2016, among others). Norris (2012) examined statutes as they compared to the Innocence Project's (2009) model standard to determine where states measured up and where they fell short of adequate assistance to exonerees. Similar to the findings of Bernhard (2004), subsequent research provided updated looks at compensation statutes and found similarly slow but sure progress in the number and quality of state compensation statutes (Gutman, 2017; Gutman \& Sun, 2019; Norris et al., 2020).

Throughout all of these compensation studies is a universal agreement that statutory awards are preferable to leaving an exoneree's fate up to litigation. Bernhard (2004) likened the pursuit of compensation without statutory remedies to a "lottery or popularity contest" (p. 708). Statutory remedies, when implemented without restrictions that can limit compensation only to individuals who didn't assist in their own conviction-meaning those who did not falsely confess - are important because they can grant compensation without subjecting exonerees to another trial and the whims of a judge or jury's determination of fair compensation. Securing compensation is particularly important as it can help predict whether an exoneree will engage in future criminality (Mandery et al., 2013). Mandery et al. (2013) found that exonerees receiving at least $\$ 500,000$ in compensation were significantly less likely to have issues with future criminality and there was no statistical difference between individuals who received less than that amount and individuals who received no compensation whatsoever.

While statutory compensation is typically presented as a more inclusive option for exonerees, it is not without its limitations, at least currently. Gutman and Sun (2019) utilized the National Registry of Exonerations to analyze the likelihood that exonerees would apply for and receive statutory compensation as compared to lawsuits filings. They found that only $~ 53 \%$ of exonerees living in states with compensation statutes filed for compensation, and of those exonerees, only $73.5 \%$ received statutory compensation. By comparison, $45 \%$ of exonerees filed tort and civil rights lawsuits, but only $55 \%$ of those filers received compensation as a result. The average compensation per year of incarceration for exonerees who received money through a lawsuit totaled more than $\$ 300,000$, an amount that far exceeds the average statutory compensation, which will be discussed more shortly (Gutman \& Sun, 2019). Winning a lawsuit thus results in greater compensation for an exoneree, but the likelihood of winning the lawsuit is lower than if exonerees had instead opted for statutory compensation. Gutman and Sun (2019) found that exonerees were more likely to apply for and receive compensation in states with "no 
fault" compensation statutes, meaning statutes that did not exclude exonerees who may have contributed to their wrongful conviction by false confession or other means (Scholand, 2019). Exonerees who were represented by innocence organizations or had been exonerated via DNA analysis were more likely to receive compensation. The takeaways from Gutman and Sun (2019) are twofold: barriers exist that prevent exonerees from filing for and/or receiving compensation, and statutory compensation is still the more reliable way to get compensation into the hands of deserving exonerees.

The problems associated with false confessions are well documented as far as causing wrongful convictions are concerned (see for example Kassin et al., 2010). As noted above, some existing compensation statutes limit or deny access to recompense if the exoneree contributed to their wrongful conviction by falsely confessing (Scholand, 2019). Though exonerees excluded from receiving compensation due to a false confession are able to file civil rights and torts lawsuits, research has highlighted that mock exonerees who falsely confessed were given less compensation by research participants than exonerees who were also declared legally innocent but had not confessed at any point (Kukucka \& Evelo, 2019). Though this research was not the first to look at the impacts of false confessions on exonerees (Clow \& Leach, 2015), it was the first to show how determinations of future compensation could be hamstrung by a false confession. A fair compensation statute that does not limit access to only certain exonerees would avoid the pitfalls of litigation by providing guaranteed assistance.

The goal of the current research is to identify the average compensation amount that exonerees could expect to receive from state statutes. When comparing this amount with opinions regarding "fair compensation" according to surveyed individuals, the current study seeks to explain how state statutes stack up to individual expectations of compensation in order to highlight the importance of continued progress toward universal access to generous statutory compensation.

\section{B. Surveys of Wrongful Convictions}

While the current research is the first to compare survey responses regarding fair compensation to existing state statutes, there have been several studies that have established public interest in wrongful convictions and support for exoneree compensation. The first few studies found that criminal justice students have knowledge about causes of wrongful convictions and attendant criminal justice issues that surpasses their peers (Bell et al., 2008; Ricciardelli et al., 2009). The current study seeks to determine whether this knowledge translates to determinations of fair compensation for exonerees. Ricciardelli and Clow (2012) found that students who hear directly from a wrongfully convicted exoneree were more likely to support government compensation for the wrongfully convicted than were peers who were not exposed to a personal story of exoneration. The public generally supports government compensation regardless of whether they are personally affected by hearing the story of an exoneree (Clow \& Ricciardelli, 2014).

There are potentially expected differences in exactly who supports compensation for exonerees based on individuals' gender, minority status, age, and political affiliation (Karaffa et al., 2015; Hicks et al., 2021). There are few known studies that directly look at how much compensation exonerees deserve. One example asked 15 respondents to share their thoughts on how much compensation was deserved, with some supporting a case-by-case determination and others believing exonerees should receive millions in compensation (Clow et al., 2012). The 
current research surveys a greater number of respondents to determine what the general sample and a student sample believes to be fair compensation.

\section{Impact of Compensation on the Criminal Justice System}

An exoneree who receives statutory compensation following their wrongful conviction, incarceration, and eventual exoneration benefits greatly, but they are not the only ones who benefit. The criminal justice system as a whole benefits from giving statutory compensation to exonerees. Receiving at least $\$ 500,000$ in compensation limits the likelihood that exonerees will commit future crimes, and simply receiving any compensation is not enough to prevent future criminality (Mandery et al., 2013). Mungan and Klick (2016) argued that large exoneree compensation serves a secondary benefit of reducing innocent individuals' guilty pleas. By increasing potential benefits to exonerees, innocent people are less averse to going to trial to try to prove their innocence (Mungan \& Klick, 2016). If this mechanism works as theorized, significant exoneree compensation would have a noticeable impact on other aspects of the criminal justice system. Reducing guilty pleas by innocent individuals would help to limit wrongful convictions and provide a benefit to the criminal justice system and society at large by lowering the number of guilty individuals that remain free to commit further crimes (Norris et al., 2019). Given the real cost in terms of money and security involved in allowing the guilty to go free, anything that can help prevent this is a positive to the system (Acker, 2013). A reduction in wrongful convictions overall would have positive effects on public opinion regarding the criminal justice system, as Norris and Mullinix (2019) highlighted that knowledge of wrongful convictions and exoneration numbers has a harmful effect on trust in the system along with diminished support for capital punishment. Lastly, public opinion helps shape governmental policy regarding exoneration and compensation such that positive public opinion regarding exonerations and compensation should lead to increases in compensation and trust in the criminal justice system (Hicks et al., 2021). When taken together, these studies highlight how exoneree compensation can have a positive impact on the criminal justice system as a whole.

\section{Current Study}

The current study builds upon previous research by examining the current state of compensation statutes and comparing them to estimations of fair compensation by individuals. As detailed below, three groups of data were collected. Students and members of the general population were surveyed to gather their opinions about what constituted fair compensation for a wrongfully convicted individual who served ten years in prison. These two groups are then compared to what each state would offer an individual who was wrongfully convicted and incarcerated for ten years according to current statutory compensation laws. The current study is exploratory in that it is the first known survey to gather opinions about fair compensation but does make several hypotheses about the expected results.

$\mathrm{H}_{1}$ : Students educated about wrongful convictions will identify a higher dollar amount as "fair compensation" for 10 years served in prison than laypersons $\mathrm{H}_{2}$ : Both surveyed groups will determine fair compensation to be significantly higher than what is actually offered by state statutes 
As the number of states offering statutory compensation continues to tick up, and original state statutes are amended and updated, the current study provides an updated and novel discussion of the current state of exoneree compensation and public expectations of fair compensation.

\section{Method}

The data collected for this research come from three sources: students enrolled in an undergraduate course on wrongful convictions, members of the general population of U.S. adults recruited through Amazon Mechanical Turk, and an analysis of existing United States wrongful convictions compensation statutes.

\section{A. Students}

110 students enrolled in a wrongful convictions course were asked at the end of the course to answer, "If you were wrongfully convicted and served 10 years in prison, how much money do you think would be fair compensation?" The National Registry of Exonerations reports an average of 9.0 years lost due to wrongful imprisonment as of July 2021; participants were asked to determine a compensation amount for 10 years to use a round number for easier calculations. Instead of providing a range of possible compensation amounts to match Kukucka and Evelo (2019), participants were asked for a compensation amount as an open-ended question to ensure that participants were not limited or biased by the possible choices.

\section{B. General Population}

100 online survey respondents were recruited using Amazon Mechanical Turk. Potential respondents were offered $\$ .05$ for successful completion of a five-question survey, with the only exclusionary criterion being that respondents must be at least 18 years or older. Respondents were asked "If you were wrongfully convicted and served 10 years in prison, how much money do you think would be fair compensation?" They were also asked to provide their gender, race/ethnicity, age, and highest education level attained. The original respondent sample included 101 respondents; 1 person was rejected from the respondent pool due to answering "yes" when asked about how much compensation should be given. The average respondent completed the task in just under 60 seconds.

\section{State Statutes}

The final data component of this research was an analysis of the compensation statutes of Washington, D.C. and all 50 United States. As of July 2021, 36 states and the District of Columbia have compensation statutes; state rules for compensation were used to calculate what an exoneree in that jurisdiction would be expected to receive after serving exactly ten years in prison. The fictional exoneree for the purposes of this research was not considered to have served their time with any extraordinary conditions such as time on death row or a sex offender registry, nor did they receive any additional compensation for days spent on probation or parole. Dollar amounts earned via state statutes similarly did not add any money for legal fees, healthcare, job or housing assistance, education, etc. so as to calculate a single number for serving ten years as a comparison to the individual responses. State statutes vary in their construction, with some having ranges of compensation and others offering a maximum compensation possible no matter how much time 
was served. Where relevant, the fictional exoneree in this research was awarded the maximum amount per year or in total. Additionally, several states award compensation based on annual household income or other statewide metrics as determined by the state, the U.S. Department of Housing and Urban Development, and the U.S. Census Bureau. The specific amounts for each state and explanations for choices made regarding individual state compensation amounts are summarized in Table 1. Of note, while New York and West Virginia have compensation statutes, compensation is determined through court filings. These states were excluded from analysis because their monetary award process is more similar to lawsuits filed by exonerees than state statutory compensation requirements.

Table 1. State Compensation Amounts for 10 Years of Incarceration

\begin{tabular}{|c|c|c|}
\hline & $\begin{array}{l}\text { Compensation for } \\
10 \text { years }\end{array}$ & Notes on Compensation Determinations \\
\hline $\mathrm{AK}$ & $\$ 0$ & \\
\hline $\mathrm{AL}$ & $\$ 500,000$ & $\$ 50,000 /$ year \\
\hline $\mathrm{AR}$ & $\$ 0$ & \\
\hline AZ & $\$ 0$ & \\
\hline CA & $\$ 511,280$ & \$140/day \\
\hline $\mathrm{CO}$ & $\$ 700,000$ & $\$ 70,000 /$ year \\
\hline $\mathrm{CT}$ & $\$ 1,598,000$ & $\begin{array}{l}\text { Up to two hundred per cent of the median household } \\
\text { income for the state/year. HUD estimate of annual } \\
\text { household income FY } 2021 \text { is } \$ 79,900\end{array}$ \\
\hline $\mathrm{DC}$ & $\$ 2,000,000$ & $\$ 200,000 /$ year \\
\hline $\mathrm{DE}$ & $\$ 0$ & \\
\hline FL & $\$ 500,000$ & $\$ 50,000 /$ year \\
\hline GA & $\$ 0$ & \\
\hline HI & $\$ 500,000$ & $\$ 50,000 /$ year \\
\hline IA & $\$ 182,600$ & $\$ 50 /$ day \\
\hline ID & $\$ 620,000$ & $\$ 62,000 /$ year \\
\hline $\mathrm{IL}$ & $\$ 121,428$ & $\begin{array}{l}\text { Prorated for } 10 \text { years based on "up to a total of } \\
\$ 170,000 \text { for imprisonment of } 14 \text { years or less but over } \\
5 \text { years" }\end{array}$ \\
\hline IN & $\$ 500,000$ & $\$ 50,000 /$ year \\
\hline KS & $\$ 650,000$ & $\$ 65,000 /$ year \\
\hline KY & $\$ 0$ & \\
\hline LA & $\$ 250,000$ & $\$ 25,000 /$ year \\
\hline MA & $\$ 1,000,000$ & Up to $\$ 1,000,000$ \\
\hline MD & $\$ 848,050$ & $\begin{array}{l}\text { Amount equal to U.S. Census Bureau estimate of } \\
\text { Maryland's annual median household income in year } \\
\text { of compensation order; } \$ 84,805 \text { as of } 2019\end{array}$ \\
\hline ME & $\$ 300,000$ & Up to $\$ 300,000$ \\
\hline MI & $\$ 500,000$ & $\$ 50,000 /$ year \\
\hline $\mathrm{MN}$ & $\$ 1,000,000$ & At least $\$ 50,000$ and not more than $\$ 100,000 /$ year \\
\hline MO & $\$ 182,600$ & $\$ 50 /$ day \\
\hline
\end{tabular}




\begin{tabular}{|c|c|c|}
\hline MS & $\$ 500,000$ & Up to $\$ 500,000$ \\
\hline MT & $\$ 600,000$ & $\$ 60,000 /$ year \\
\hline $\mathrm{NC}$ & $\$ 500,000$ & $\$ 50,000 /$ year \\
\hline ND & $\$ 0$ & \\
\hline NE & $\$ 500,000$ & Up to $\$ 500,000$ \\
\hline $\mathrm{NH}$ & $\$ 20,000$ & Up to $\$ 20,000$ total \\
\hline NJ & $\$ 500,000$ & $\begin{array}{l}\text { Greater of (a) twice the exoneree's income in the year } \\
\text { prior to incarceration, or (b) } \$ 50,000 \text { for each year of } \\
\text { incarceration }\end{array}$ \\
\hline NM & $\$ 0$ & \\
\hline NV & $\$ 500,000$ & $\begin{array}{l}1-10 \text { years }=\$ 50,000 \text { per year of wrongful } \\
\text { incarceration }\end{array}$ \\
\hline NY & N/A & Determined by Court of Claims \\
\hline $\mathrm{OH}$ & $\$ 567,524$ & $\begin{array}{l}\text { As of } 1 / 27 / 2021, \$ 56,752.36 / \text { year; recalculated every } \\
\text { two years }\end{array}$ \\
\hline OK & $\$ 175,000$ & Up to $\$ 175,000$ \\
\hline OR & $\$ 0$ & \\
\hline PA & $\$ 0$ & \\
\hline RI & $\$ 0$ & \\
\hline $\mathrm{SC}$ & $\$ 0$ & \\
\hline SD & $\$ 0$ & \\
\hline TN & $\$ 1,000,000$ & Up to $\$ 1,000,000$ \\
\hline TX & $\$ 800,000$ & $\$ 80,000 /$ year \\
\hline UT & $\$ 498,360$ & $\begin{array}{l}\text { Average annual nonagricultural payroll wage in Utah } \\
\text { at the time of release/year; } \$ 4,153 / \text { month as of } 2019\end{array}$ \\
\hline VA & $\$ 353,502$ & $\begin{array}{l}90 \% \text { of the inflation-adjusted Virginia per capita } \\
\text { personal income/year; Per capita VA income as of } \\
\text { 2019: } \$ 39,278\end{array}$ \\
\hline VT & $\$ 600,000$ & Between $\$ 30,000$ and $\$ 60,000 /$ year \\
\hline WA & $\$ 500,000$ & $\$ 50,000 /$ year \\
\hline WI & $\$ 25,000$ & Maximum of $\$ 25,000$ \\
\hline WV & N/A & Court determined \\
\hline WY & $\$ 0$ & \\
\hline $\begin{array}{l}\text { Average } \\
\text { (States with } \\
\text { Compensation } \\
\text { ) }\end{array}$ & $\$ 574,381$ & \\
\hline $\begin{array}{l}\text { Average } \\
\text { (All states) }\end{array}$ & $\$ 410,272$ & \\
\hline
\end{tabular}




\section{Results}

\section{A. Students}

On average, students were the most generous with their determinations of fair compensation, as predicted by $\mathrm{H}_{1}$. The average compensation for ten years in prison reported by students exceeded $\$ 15.3$ million, a figure that is more similar to wrongful conviction payouts given by juries in successful compensation lawsuits than any state statutory compensation, as shown below. However, the average amount given by students was clearly affected by an outlier that awarded \$1 billion; when this amount is removed, the average drops to just $\$ 6.35$ million. The most popular responses clustered around large round numbers, with 62 of 110 respondents determining fair compensation to be either $\$ 1$ million, $\$ 5$ million, or $\$ 10$ million. All responses are shown in Figure 1.

\section{B. General Population}

Compared with students, participants in the general population were more moderate in their determinations of fair compensation. The average compensation for serving ten years in prison due to a wrongful conviction was just under $\$ 6.0$ million. Though this average amount included outliers at both ends of the continuum, as one respondent awarded $\$ 0$ in compensation and another awarded \$100 million, excluding the lowest and/or highest awards does not significantly impact the resulting average. As with student responses, the most popular responses clustered around large round numbers, with 51 of 100 respondents determining fair compensation to be either $\$ 500,000$, $\$ 1$ million, $\$ 5$ million, or $\$ 10$ million. All responses are shown in Figure 1.

\section{State Statutes}

As expected, even the most generous of state statutes pales in comparison to the numbers given by individual respondents. Among the 34 states and the District of Columbia which have monetary compensation statutes, the average compensation as calculated by the assumptions laid out in Table 1 was $\$ 574,381$. When including the states that have no compensation statutes, which would represent the average compensation received by an exoneree anywhere in the U.S., the average drops to $\$ 410,272$. As a reminder, New York and West Virginia are excluded from these numbers since their compensation statutes provide for court decisions rather than a determinable amount. 
Figure 1. Compensation Amounts Specified by Respondents

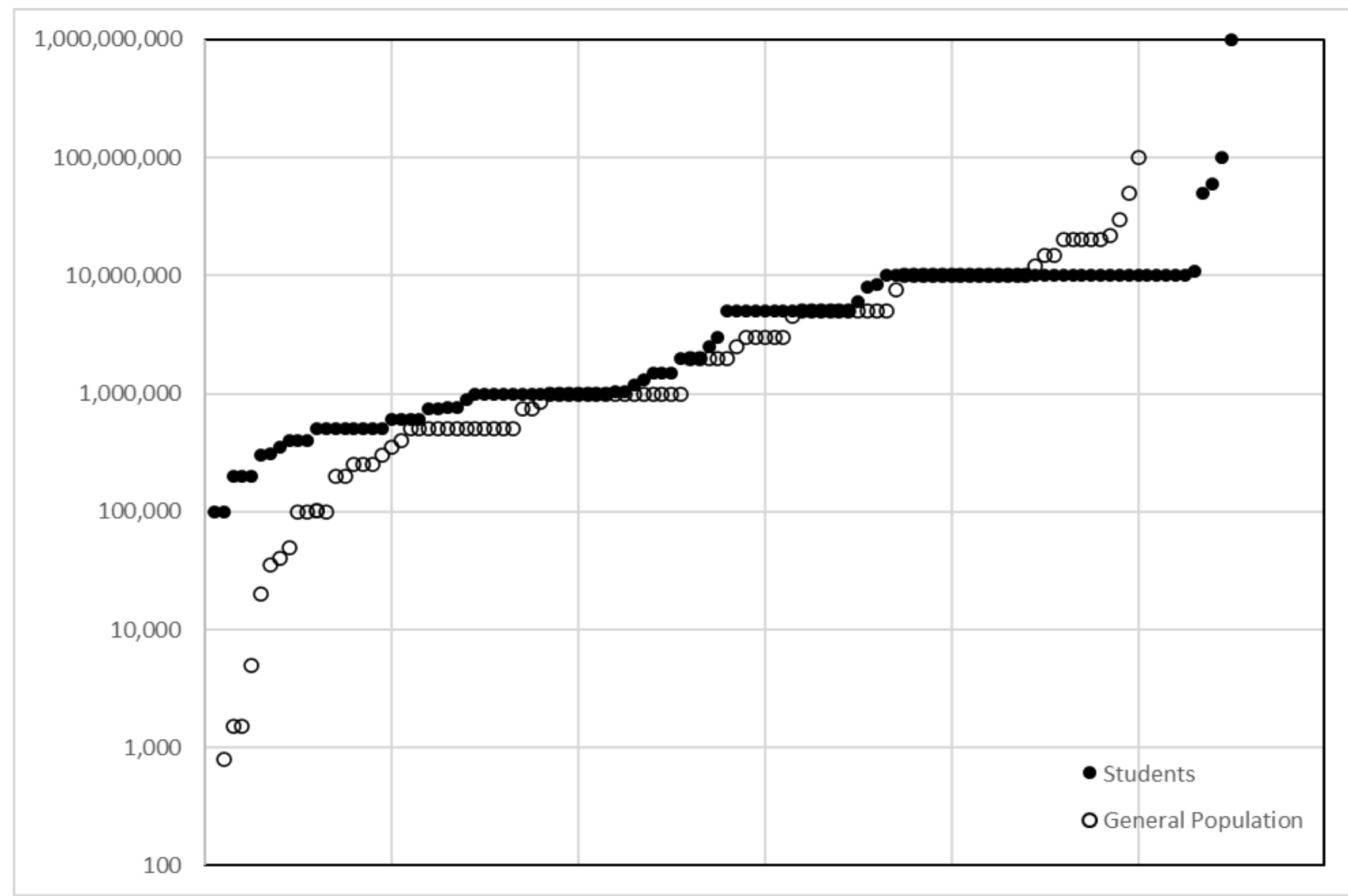

\section{Hypotheses and Other Considerations}

A $t$-test $(\mathrm{t}=2.287, p=.023)$ found that there was significant variation in compensation amounts determined by individual respondents and state statutes. However, a one-way ANOVA finds no significant difference of average compensation awarded between students, general population, and state statutes $(\mathrm{F}=1.142, p=.321)$. As noted above, Hypothesis 1 predicted that students would specify the highest amount of fair compensation. This was supported by the current findings in terms of raw dollar amounts, whether outlying answers were included or not. However, Hypothesis 2 predicted a significant different in dollar amounts determined by individuals as compared with state statutes, but the amounts given by each group are not significant. While statistically this is the case, there is a figuratively significant difference in being awarded the student average of $\$ 15,383,768$ and the state statute average of $\$ 573,893$. The meaning of this finding will be discussed shortly.

It is worth briefly mentioning that nothing meaningful was found when calculating average compensation by race, age, gender, or education levels. Perhaps more respondents would return noteworthy results, but this is difficult to determine because asking for raw compensation numbers makes outlying values likely and difficult to determine their meaning (e.g., one female respondent answered $\$ 100$ million; the inclusion of this amount changes the average female compensation by almost \$2 million). Future research should explore whether there are gender, age, race, or education differences in compensation amounts deemed "fair". 


\section{Discussion}

The current research finds that there is no statistically significant difference between the average compensation given to exonerees who were wrongfully incarcerated for ten years via state statute, and the amounts that individuals thought was "fair compensation" for that same amount of time. This is unexpected, as Hypothesis 2 in this study anticipated finding significant differences between statutory compensation and perceptions of fair compensation. It is unlikely that an exoneree would willingly choose the smaller amount of compensation over the larger under the guise of the amounts not being statistically different, but exonerees are faced with a similar choice. Since many states require the waiver of the right to sue the state and criminal justice system actors as a condition of accepting statutory compensation, exonerees frequently must give up chances at large payouts for smaller, more guaranteed amounts.

The variability seen in perceptions of fair compensation by individual participants is likely comparable to the variability seen in exoneree compensation lawsuits. While respondents in this research were almost unanimously supportive of compensation for exonerees, this variability is something that states would no doubt find unwelcome. In the current research, only one respondent did not award any compensation, and only nine suggested anything less than six figures in compensation. Exonerees have a low success rate in securing compensation at trial (Bernhard, 1999; Lonergan, 2008). Though they are more likely to receive statutory compensation, the amounts given by juries, judges, and state compensation boards far exceeds the statutory norm (Gutman \& Sun, 2019). That exonerees do not always apply for statutory compensation and all applicants do not receive compensation also must be addressed (Gutman \& Sun, 2019). Universal access to statutory compensation would provide compensation to more exonerees while giving states a better chance at anticipating and budgeting for compensation costs.

In the near term, it is expected that exonerees will see increases in the number of states offering statutory compensation as well as the amount of compensation that those statutes provide. While 14 states as of July 2021 do not offer statutory compensation, Pennsylvania's 2021-2022 budget as proposed by the Governor included a request for compensation, so we should expect to see fewer states that wholly lack compensation statutes soon. As more states add compensation statutes that meet or exceed the Innocence Project's (2009) recommended model standard, the outlook for exonerees improves. This is especially important in light of Mandery et al.'s (2013) finding that future criminality significantly decreases as compensation to exonerees exceeds $\$ 500,000$. If only states with current compensation statutes are examined, the average compensation for ten years of wrongful incarceration exceeds that $\$ 500,000$ threshold.

\section{A. Limitations and Future Research}

The current research was intended as an exploratory study to determine whether there were significant differences between what individuals believed constituted fair compensation and what state statutes would provide to exonerees. The current study is limited in scope and would benefit from a replication using a greater sample size. Karaffa et al. (2015) found that males, minorities, and older individuals thought exonerees were more deserving of compensation; because of a limited sample size, the current study was unable to test whether these findings would also hold for individual award determinations. Future research should explore whether demographic factors such as gender, race or ethnicity, age, and education level impact perceptions of fair compensation. 
The findings of Hicks et al. (2021) would predict that self-reported political ideology would similarly impact the magnitude of fair compensation, but this should be explored in future research.

Another weakness of the current research is that individual respondents were not asked additional questions or given material related to compensation, they were only asked to provide one number regarding fair compensation. A more complex questioning of individuals regarding compensation, their perceptions of current state statutes, how they would pay for compensation to exonerees, among other questions, would provide a more complete picture of an individual's views on compensation. It is reasonable to believe that individuals who are asked to report their feelings on fair compensation are not taking into account factors that government officials must. Prior research has suggested this may be the case, so further research should examine whether details about paying for compensation impacts the likelihood and amount of compensation given by individuals (Zalman et al., 2012). Finally, future research is planned to determine whether individuals would grant different compensation to a fictional exoneree than they would grant themselves if they were in the unenviable position of being wrongfully convicted.

\section{B. Concluding Remarks}

That compensation should be provided to exonerated individuals has been a common argument in the scientific literature and popular culture for more than two decades. The current research shows that progress has been made regarding the number of states offering statutory compensation, but that perceptions of fair compensation outpace what is actually available to exonerees. There has been progress in the number of state statutes regarding compensation, and the increases in the amounts exonerees can expect to see. Through advocacy by organizations like the Innocence Project and individuals, both exonerees and concerned citizens, future research will hopefully be discussing that all 50 states offer generous compensation to wrongfully convicted individuals. It is important that research, advocacy, and public pressure continues to press state governments to act to ensure that exonerees do not suffer further injustices at the hands of the criminal justice system.

\section{References}

Acker, James R. (2013). The flipside injustice of wrongful convictions: When the guilty go free. Albany Law Review, 76, 1629-1712.

Bell, James G., Clow, Kimberley A., \& Ricciardelli, Rosemary. (2008). Causes of wrongful conviction: Looking at student knowledge. Journal of Criminal Justice Education, 19(1), 75-96, online: https://doi.org/10.1080/10511250801892979.

Bernhard, Adele. (1999). When justice fails: Indemnification for unjust conviction. University of Chicago Law School Roundtable, 6, 73-112.

Bernhard, Adele. (2004). Justice still fails: A review of recent efforts to compensate individuals who have been unjustly convicted and later exonerated. Drake Law Review, 52, 703-738.

Bernhard, Adele. (2009). A short overview of the statutory remedies for the wrongly convicted: What works, what doesn't, and why. Public Interest Law Journal, 18, 403-425. 
Chunias, Jennifer L., \& Aufgang, Yael D. (2008). Beyond monetary compensation: The need for comprehensive services for the wrongfully convicted. Boston College Third World Law Journal, 28(1), 105-128, online: https://lawdigitalcommons.bc.edu/twlj/vol28/iss1/3.

Clow, Kimberley A., Blandisi, Isabella, Ricciardelli, Rosemary, \& Schuller, Regina. (2012). Public perception of wrongful conviction: Support for compensation and apologies. Albany Law Review, 75, 1415-1438.

Clow, Kimberley A., \& Leach, Amy-May. (2015). Stigma and wrongful conviction: All exonerees are not perceived equal, Psychology, Crime \& Law, 21(2), 172-185, online: https://doi.org/10.1080/1068316X.2014.951645.

Clow, Kimberley A., \& Ricciardelli, Rosemary. (2014). Public perceptions of wrongful conviction. Canadian Criminal Law Review, 18, 183-198.

Gutman, Jeffrey S. (2017). An empirical reexamination of state statutory compensation for the wrongly convicted. Missouri Law Review, 82(2), 369-440.

Gutman, Jeffery S., \& Sun, Lingxiao. (2019). Why is Mississippi the best state in which to be exonerated? An empirical evaluation of state statutory and civil compensation for the wrongly convicted. Northeastern University Law Review, 11(2), 694-789.

Hicks, William, Mullinix, Kevin, \& Norris, Robert. (2021). The politics of wrongful conviction legislation. State Politics \& Policy Quarterly, 1-20, online:

https://doi.org/10.1017/spq.2020.4.

Innocence Project. (2009). Making up for lost time: What the wrongfully convicted endure and how to provide fair compensation. Retrieved from online:

https://www.innocenceproject.org/wpcontent/uploads/2016/06/innocence_project_compensation_report-6.pdf.

Karaffa, Kerry M., Page, Jaimie, \& Koch, Julie M. (2015). Compensating the innocent: Perceptions of exonerees' deservingness to receive financial compensation for wrongful convictions. Criminal Justice Policy Review, 28(7), 710-732, online: https://doi.org/10.1177/0887403415607049.

Kassin, Saul M., Drizin, Steven A., Grisso, Thomas, Gudjonsson, Gisli H., Leo, Richard A., \& Redlich, Allison D. (2010). Police induced confessions: Risk factors and recommendations. Law and Human Behavior, 34, 3-38, online:

https://doi.org/10.1007/s10979-009-9188-6.

Kukucka, Jeff, \& Evelo, Andrew J. (2019). Stigma against false confessors impacts postexoneration financial compensation. Behavioral Sciences \& the Law, 37(4), 372-387, online: https://doi.org/10.1002/bsl.2403.

Lonergan, Jessica R. (2008). Protecting the innocent: A model for comprehensive, individualized compensation of the exonerated. Legislation and Public Policy, 11, 405-452.

Mandery, Evan, Shlosberg, Amy, West, Valerie, \& Callaghan, Bennett. (2013). Compensation statutes and postexoneration offending. The Journal of Criminal Law and Criminology, 103(2), 553-583.

Melamed, Samantha. (2021, June 13). As Philly tops two dozen exonerations, city may face tens of millions in civil liability. Philadelphia Inquirer, online: 
https://www.inquirer.com/news/wrongful-convictions-philadelphia-civil-settlementslawsuits-20210613.html.

Mostaghel, Deborah. (2011). Wrongfully incarcerated, randomly compensated - How to fund wrongful-conviction compensation statutes. Indiana Law Review, 44, 503-544.

Mungan, Murat C., \& Klick, Jonathan. (2016). Reducing false guilty pleas and wrongful convictions through exoneree compensation. The Journal of Law and Economics. 59(1), 173-189, online: https://doi.org/10.1086/684686; National Registry of Exonerations. Longest Incarcerations. https://www.law.umich.edu/special/exoneration/Pages/longestincarceration.aspx

Norris, Robert J. (2012). Assessing compensation statutes for the wrongly convicted. Criminal Justice Policy Review, 23(3), 352-374, online: https://doi.org/10.1177/0887403411409916.

Norris, Robert J., \& Mullinix, Kevin J. (2019). Framing innocence: An experimental test of wrongful convictions and public opinion. Journal of Experimental Criminology, 16, 31134, online: https://doi.org/10.1007/s11292-019-09360-7.

Norris, Robert J., Weintraub, Jennifer N., Acker, James R., Redlich, Allison D., \& Bonventre, Catherine L. (2020). The criminal costs of wrongful convictions: Can we reduce crime by protecting the innocent? Criminology \& Public Policy, 19, 367-388, online: https://doi.org/10.1111/1745-9133.12463.

Possley, Maurice. (2021a). Walter Ogrod. The National Registry of Exonerations, online: https://www.law.umich.edu/special/exoneration/Pages/casedetail.aspx? caseid=5752.

Possley, Maurice. (2021b). Lacino Hamilton. The National Registry of Exonerations, online: https://www.law.umich.edu/special/exoneration/Pages/casedetail.aspx? caseid=5828.

Ricciardelli, Rosemary, Bell, James G., \& Clow, Kimberley A. (2009). Student attitudes toward wrongful conviction. Canadian Journal of Criminology and Criminal Justice, 51, 411427, online: https://doi.org/10.3138/cjccj.51.3.411.

Ricciardelli, Rosemary, \& Clow, Kimberley A. (2012). The impact of an exonoree's guest lecture on students' attitudes toward wrongly convicted persons. Journal of Criminal Justice Education, 23(2), 127-147, online: https://doi.org/10.1080/10511253.2011.590512.

Scholand, Gregory P. (2013). Re-punishing the innocent: False confession as an unjust obstacle to compensation for the wrongfully convicted. Case Western Reserve Law Review, 63, 13931418.

Simms, Tina. (2016). Statutory compensation for the wrongly imprisoned. Social Work, 61(2), 155-162, online: https://doi.org/10.1093/sw/sww003.

Zalman, Marvin, Larson, Matthew J., \& Smith, Brad. (2012). Citizens' attitudes toward wrongful convictions. Criminal Justice Review, 37, 51-69, online:

https://doi.org/10.1177/0734016811428374. 